\title{
Cost Effective Technique of Removal of Platelets for HLA Crossmatching by Density Gradient Centrifugation
}

\author{
Murali Adiga* \\ Department of Physiology, Kasturba Medical College, MAHE, Manipal, Karnataka, \\ India \\ *Corresponding Author: Murali Adiga, Department of Physiology, Kasturba Medical \\ College, MAHE, Manipal, Karnataka, India.
}

Received: February 05, 2020

Published: September 30, 2020

(C) All rights are reserved by Murali Adiga.

\section{Abstract}

Renal transplantation is the most successful treatment option for chronic renal failure patients. But success of this depends on HLA crossmatching between the renal recipient and donor. In this test, RBCs and platelets are removed and only donor lymphocytes are incubated with recipient's serum and the complement and percentage of dead lymphocytes is documented. More than $5 \%$ of dead cells indicates a positive test and is a contraindication for renal transplantation. For HLA crossmatching, platelets must be removed before lymphocytes mixed with serum. Removal of platelets for crossmatching by traditional method is a very expensive procedure till now as commercially available thrombin is very costly, which increases the financial burden of the patients. Therefore, we tried to develop a cost effective technique to remove platelets by density gradient centrifugation in patients and donors visiting the Nephrology department of Kasturba Hospital, Manipal. After removing plasma and red blood cells, cell suspension in MCT vials is centrifuged @ 1000 rpm for 5 minutes using microcentrifuge. After this, supernatant is discarded and cell pellet is resuspended with buffer and again centrifuged @ 1000 rpm for 5 minutes. This step is repeated 4 or 5 times until the cell suspension is completely cleared off platelets. A total of 96 HLA crossmatching tests done on renal transplant patients and donors visiting Kasturba Hospital, Manipal. Out of this, two cases showed 5\% platelets even after 5 times centrifugation. When we centrifuged the cell suspension @ 1000 rpm for 5 minutes, less denser platelets remained in supernatant and more denser lymphocytes sediment to the bottom. When this is repeated 4 or 5 times, all the platelets are removed. This is a very cost effective technique compared to commercial thrombin used earlier, which has reduced the cost of HLA crossmatching.

Keywords: HLA Crossmatch; MCT Vials; CRF

\section{Introduction}

Renal transplantation is the most successful treatment option for chronic renal failure (CRF) or end stage renal disease (ESRD) patients. But success of this depends on HLA crossmatching between the renal recipient and donor. It is done to check if the renal transplant recipient has been previously sensitized and has circulating antibodies in his/her serum, which reacts with donor HLA antigens thereby resulting in hyper acute rejection of graft. In this test, RBCs and platelets are removed and only donor lymphocytes are incubated with recipient's serum and the complement and percentage of dead lymphocytes is documented. More than $5 \%$ of dead cells indicates a positive test and is a contraindication for renal transplantation. A negative crossmatch indicates that the patient does not have HLA antibody against that particular donor, and a transplant can be performed. For HLA crossmatching, platelets must be removed before lymphocytes mixed with serum. Removal of platelets for crossmatching is a very expensive procedure till now as commercially available thrombin is very expensive, which increases the financial burden of the patients. Therefore, we tried to develop a cost effective, gentle on the platelets and simple tech- 
nique to remove platelets by density gradient centrifugation in patients and donors visiting the Nephrology department of Kasturba Hospital, Manipal.

The usual route for sensitisation towards HLA antigens occurs in three instances; pregnancy, post blood transfusion and prior transplantation. Preformed antibodies increase the chances of immunological failure of the allograft by causing positive crossmatches and, thereby, result in the exclusion of donors [1].

A number of methods have been developed to isolate blood platelets. The most common methods involve centrifugation, which can activate or damage platelets, especially when they are pelleted several times. Gentler methods have been developed using density gradient centrifugation [2-4] or electrophoresis [5] but these methods tend to be quite time consuming or require specialized equipment or expertise. Recently a density gradient centrifugation technique was reported that is faster but still produces a relatively dilute platelet preparation [6]. Hoffman [7] developed a technique that allows the rapid isolation of functionally intact purified platelets. It requires no specialized expertise or equipment or expensive reagents. That technique also allows platelets to be concentrated to the point that platelet function studies can be performed on samples from moderately thrombocytopenic patients.

In blood banks, platelets concentrate is prepared by two spins. First, using light spin, platelet rich plasma (PRP) is obtained. Then heavy spin of PRP is done to sediment platelets to the bottom to get platelet concentrate for patients. We tried to apply the same principle of density gradient centrifugation for removing platelets for HLA crossmatching in HLA lab of our hospital.

\section{Materials and Methods}

This study was duly started after obtaining mandatory clearance from Institutional Ethical Committee of Kasturba Hospital (-IEC-372/2014).

HLA crossmatching was performed by complement dependent lymphocytotoxicity (CDC) assay, which was first developed in 1960s.

\section{Cell separation}

$10 \mathrm{ml}$ whole blood is collected from patient and donor and anticoagulated with acid citrate dextrose (ACD) $(2 \mathrm{ml}$ ACD $+10 \mathrm{ml}$ blood). ACD anticoagulated blood is centrifuged at $3000 \mathrm{rpm}$ for
15 minutes. Plasma is removed and buffy coat is transferred into separate tube $(15 \mathrm{ml})$ containing $3 \mathrm{ml}$ RPMI. Then buffy coat is layered over $3 \mathrm{ml}$ Histopaque, taken in other tube. Then centrifuged at $3000 \mathrm{rpm}$ for 15 minutes. Interface is transferred into a $15 \mathrm{ml}$ centrifuge tube containing $5 \mathrm{ml}$ RPMI. Spinned @1000 rpm for 5 minutes. Discarded supernatant. Added 2 ml Tris $\mathrm{NH}_{4} \mathrm{Cl}$ (RBC Lyses fluid) to the pellet. Pellet is dispersed and kept at RT for 5 minutes. Spinned @ 1000 rpm for 5 minutes. Discard supernatant, add $5 \mathrm{ml}$ RPMI and mix, centrifuge at 1000 rpm for 5 minutes. Discard supernatant, add 5 ml RPMI mix thoroughly. Spin @ 1000 rpm form 5 minutes. (During this step prepare RPMI-FCS solution by adding 50 ul FBS to $5 \mathrm{ml} \mathrm{RPMI} \mathrm{media} \mathrm{and} \mathrm{centrifuge} 3000$ rpm for 5 minutes). Discard the supernatant, add $4 \mathrm{ml}$ RPMI-FCS solution centrifuge at $1500 \mathrm{rpm}$ for 10 seconds. Transfer supernatant to MCT vials, previously rinsed with RPMI. (Pt cells and Donor cells). Centrifuge at 5000 rpm for 2 minutes. Discard supernatant; suspend the pallet with RPMI-FBS. (Add RPMI depending on the size of the pallet). Charge Neubauer chamber for purity check. If macromolecules present - centrifuge at $3000 \mathrm{rpm}$ for 3 seconds. Transfer supernatant. If platelets present - centrifuge at $1000 \mathrm{rpm}$ for 5 minutes. Discard supernatant (light spin) resuspend deposit with RPMI. Check for viability of lymphocytes: By dye exclusion method is using trypan blue solution. Mix 1 drop of cell suspension and 1 drop of trypan blue in a microfuge tube. Then charge the chamber. Dead cells take up the dye and appear blue in color while it is excluded from live cells. Count dead cells first within 3 minutes. Followed by total cells and viability is expressed as $\%$.

$\%$ viability $=$ Total cells - dead cells $\mathrm{X} 100$

Total cells

Ideally \% viability should be $>90 \%$.

For plating, cell count has to be adjusted to 2000 - 3000 cells/ ul. To get this count, adjust 200 - 250 cells per one WBC square. If count is higher, cell suspension is appropriately diluted with RPMI. While if counts are lower, it has to be concentrated by centrifuging and discarding the supernatant.

Now the cell suspension is ready for plating.

\section{Serum preparation}

After blood is clotted, centrifuge at $3000 \mathrm{rpm}$ for $10 \mathrm{mins}$.Transfer serum to MCT tube and keep it in $-20^{\circ} \mathrm{C}$ temp for 30 minutes. 
Keep it RT for 10 min, centrifuge at 3000 rpm for 5 minutes. Transfer the supernatant to another MCT tube and place this undiluted serum (Neat) in the rack for serum dilution. Besides keep 2 micro centrifuge tubes for $\mathrm{N} / 2$ and N/4. Add $100 \mathrm{ml}$ PBS into each of 2 microfuge tubes (N/2 and N/4). Now add $100 \mathrm{ml}$ neat serum $(\mathrm{N})$ to $\mathrm{N} / 2$ microfuge tube. Mix well and transfer $100 \mathrm{ml}$ to $\mathrm{N} / 4 \mathrm{mi}$ crofuge tube. Now the patient serum is ready for plating. Once the cells (both patient and donor) and sera are ready, crossmatching is done by mixing patient sera with donor cells. Also, positive control and negative control run simultaneously.

\section{Method of tray dotting}

A sterile 72 well Terasaki tray is taken. Add $5 \mathrm{ml}$ oil to all wells. Add $1 \mathrm{ml}$ diluted serum, -ve control and PBS to appropriate wells. Add $1 \mathrm{ml}$ Donor cells and pt cells to appropriate wells. Now add $1 \mathrm{ml}+\mathrm{ve}$ control to respective wells. Mix, ensure addition of cells to all wells by observing under microscope. Incubate at RT for 1 $\mathrm{hr}$. Add $5 \mathrm{ml}$ compliment to all wells. Incubate at RT for $2 \mathrm{hr}$. Add $5 \mathrm{ul}$ eosin to all wells. After 2 minutes, add $5 \mathrm{ml} 20 \%$ formalin to all wells. Cover slipped, closed with lid, store at $4^{\circ} \mathrm{C}$ overnight. The percentage of dead lymphocytes in the test wells is documented using inverted phase contrast microscope. More than $5 \%$ of dead lymphocytes in the test wells are interpreted as positive test, which is a contraindication for renal transplantation.

\section{Results}

After removing plasma and red blood cells, cell suspension in MCT vials is centrifuged @ 1000 rpm for 5 minutes using microcentrifuge. After this, supernatant is discarded and cell pellet is resuspended with buffer and again centrifuged @ 1000 rpm for 5 minutes. This step is repeated 4 or 5 times until the cell suspension is completely cleared off platelets. Platelet free lymphocyte cell suspension is mixed with sera and crossmatching is continued. A total of 96 HLA crossmatching tests done on renal transplant patients and donors visiting Kasturba Hospital, Manipal. Out of this, two cases showed 5\% platelets even after 5 times centrifugation. In these case, traditional thrombin method for removal of platelets is followed.

\section{Conclusion}

When we centrifuged the cell suspension @ 1000 rpm for 5 mins, less denser platelets, because of their small size, sediment much more slowly and therefore remained in the supernatant. On the other hand more denser lymphocytes sediment to the bottom quickly due to their large size. When this is repeated 4 or 5 times and supernatant is discarded, all the platelets are removed. This is a very cost effective technique compared to commercial thrombin used earlier, which has reduced the cost of HLA crossmatching by around two to three times.

\section{Bibliography}

1. Tinckam KJ. "Basic histocompatibility testing methods". In: Chandraker A, editor. Core concepts in renal transplantation". New York: Springer Science + Business Media, LLC (2012): 2142.

2. Ganguly P and Sonnichsen WJ. "A simple method for the isolation of blood platelets". Journal of Clinical Pathology 26 (1973): 635-637.

3. Imandt L., et al. "An improved method for preparing platelet rich plasma". Thrombosis Research 11 (1977): 429-432.

4. Levy-Tolendano S., et al. "Isolation and function of platelets. II. A new method using total blood:metrizamide gradient centrifugation". Nouvelle Revue Française D’hématologie 16 (1976): 367-380.

5. Wilson RBJ and Graham JM. "Isolation of platelets from human blood using freeflow electrophoresis". Clinica Chimica Acta 159 (1986): 211-217.

6. Ford TC., et al. "A new. rapid. one-step method for the isolation of platelets from human blood". Clinica Chimica Acta 192 (1990): 15-120.

7. Hoffman M., et al. "A rapid method to isolate platelets from human blood by density gradient centrifugation". American Journal of Clinical Pathology 98.5 (1992): 531-533.

\section{Assets from publication with us}

- Prompt Acknowledgement after receiving the article

- Thorough Double blinded peer review

- Rapid Publication

- Issue of Publication Certificate

- High visibility of your Published work

Website: www.actascientific.com/

Submit Article: www.actascientific.com/submission.php

Email us: editor@actascientific.com

Contact us: +919182824667 